\title{
Protected areas: a valid argument for the renovation and diversification of mature coastal tourist destinations in Spain?
}

\author{
I. Rodríguez, M. P. Such \& M. Capdepón \\ Institute for Tourism Research, University of Alicante, Spain
}

\begin{abstract}
During the last two decades, tourism policies in Spain have had as a priority objective the diversification and differentiation of tourist destinations, together with the improvement of service and infrastructure quality levels as the best strategies to guarantee the competitiveness of tourism activity. Although Spain has managed to maintain its leadership as a sun and sand tourist destination, the strategies undertaken up to the present day have failed to achieve a real change in the tourism dynamics that must respond to the new demand trends and the challenge of sustainability. In this respect, before the apparent need for renovation, mature tourist destinations should insist on the enhancement of their offer through the valorisation of territorial components and particularly those associated with the protected areas that still survive after the urban process that most tourist destinations have characteristically gone through. In fact, both town-development and the mechanisms for the creation of new accommodation infrastructures and residential homes have seriously threatened the environment of protected areas and have had an influential role on the environmental impact of coastal areas. This paper seeks to present the diagnosis and conclusions obtained about the role that protected areas may play in the diversification of the tourist offer through the optimal enhancement of their public use. Based on empirical findings from Serra Gelada Natural Park, located in the Benidorm tourist destination, key issues related to the tourism strategies recently developed for protected areas are explored focusing on the potential to create new nature-based tourism products.
\end{abstract}

Keywords: protected areas, public use, renovation, diversification, mature coastal destinations, nature-based tourism products. 


\section{Theoretical introduction}

Following the Tourist Area Life Cycle theory proposed by Richard W. Butler, a reference model to describe the evolution processes of tourist destinations according to Vera et al. [1], it can be stated that the sun and sand specialised mass tourism that is characteristic of the Spanish coast in general and the Valencian Region in particular is going through a consolidation stage that is near stagnation and, perhaps, even approaching a relative decline, in sharp contrast with the rapid expansion of other more flexible tourism modalities [2]. As Perelli and Prats [3] have pointed out, these destinations are additionally facing a new scenario resulting from the effects of globalisation and the challenges posed by climate change as well as by the sector itself, where changes in the tourist supply and demand are increasingly deep and fast (new business models, low-cost airlines, on-line distribution, etc.). Far from certain approaches like the Life Cycle Theory, which refer to a supposed and inevitable decline of Mediterranean mature destinations [4], other authors such as Antón [5] suggest more positive scenarios claiming that the figures seem to indicate that, in the medium term, Mediterranean seaside tourism will continue to be the most relevant appeal for the emitting markets which currently have Spain as their target destination. In Vera's words [6], it can be said that we find ourselves in front of a new tourism stage where one of the essential challenges for the future lies in maintaining and qualifying tourist activity from the principles of sustainability and competitiveness. Along these same lines, many other authors have highlighted that the situations experienced must make us reflect so that we can reorient 'the model' towards the search for sustainability. That aim makes it necessary to restructure tourist activity and generate differentiated products based on natural and cultural resources [7].

It thus becomes obvious that, within the current regressive context regarding the number of international visitors, the need to think of new strategies for the rejuvenation or renovation of coastal tourist destinations and areas acquires even more importance. For Agarwal [8], there are two main types of restructuring, namely the transformation of the product and its reorganisation. Instead, Butler [9] argues that the extension of the life cycle can be achieved by means of diversification through the construction of new attractions and the exploitation of natural resources which had not previously been commercialised. That is why the receiving areas are striving to insert new elements and exploit resources which had still not been sufficiently exploited, seeking to create new tourism products, among which stand out some linked to nature tourism, with the ultimate aim of qualifying and diversifying the coastal resort offer.

Regarding the considerations above, the present study places emphasis on the exploitation of the natural environment through the proposal of activities in the open air and the shaping of active tourism offers largely connected with the valorisation of PNAs. More precisely, these starting premises serve to undertake a line of work for Benidorm, a consolidated destination par excellence and, in all respects, one of the main mass-tourism resorts along the Spanish Mediterranean coastline. The idea would therefore be to assess the possibilities of diversifying 
its tourist offer by putting Sierra Gelada Natural Park in value. A number of possible proposals for action have been elaborated to that end.

\section{The current tourism policy oriented to the renovation and sustainability of consolidated tourist destinations}

Before the present-day context, defined by a worldwide economic crisis and the maturity of Spanish coastal destinations, restructuring and renovation have now become a need that is widely recognised by both public and private agents. In fact, Spain's current tourism policy has based its strategic orientation on goals which respond to that need: the consolidation of leadership, the differential positioning of the offer, sustainability, and the incorporation of the innovation culture, amongst others. These goals are contained in the Plan del Turismo Español Horizonte 2020 [Horizon 2020 Spanish Tourism Plan] [10], approved at the end of 2007 by the Ministry of Industry, Tourism and Commerce as the planning document which seeks to draw the strategic lines of the Spanish tourism policy. This Plan recognises that the sun and beach product still represents the pillar of Spanish tourism but also highlights the need to improve and strengthen its competitiveness, which means working on the qualification of 'mature' tourist destinations. The diagnosis offered by this Plan focuses on the environmental deterioration of a high number of destinations caused not only by an excessive and disorganised urban growth but also by the 'old age' of part of the hotel establishments, especially in the sun and beach segment. The document also explicitly acknowledges the gradual reduction in profitability of the sun and beach product, which accounts for $75 \%$ of the receiving demand.

This plan also underlines the need to create tourism products based on the identity and singularity of destinations, to increase the competitiveness of the existing products and to reinforce the value of the experience offered to the tourist. It equally suggests giving a boost to the creation of special-interest products and experiential routes and tourism products which provide resources with a high cultural and natural potential; objectives and proposals, all of which could be linked to the putting in value of PNAs as an element of diversification and qualification for consolidated destinations. The Plan includes as another part of the Sustainability Axis within Spain's tourism model a specific Tourism, Environment and Society programme which has materialised in the report entitled "Configuration of new nature tourism products", which establishes two broad action lines:

- Implementation of the Spanish System for the Adhesion of Spanish tourism firms to the European Charter for Sustainable Tourism in Protected Areas (CETS) accredited by it. This document, which arose as an initiative of the EUROPARC Federation, has as its aim to promote a sustainable development of tourism in European PNAs and requires the voluntary commitment of managers, tourism firms and tour-operators.

- Tourism Product "Reservas de la Biosfera Españolas" [Spanish Biosphere Reserves]. The Network of Spanish Biosphere Reserves includes 38 territories which stand out for their high natural value and which place at 
our disposal a potentially wide range of new products that have not been exploited to a large extent yet. The objective is to have available a manual of the product Spanish Biosphere Reserves which can specify the requirements for the participation of its integrating elements.

\section{Protected natural spaces and renovation of the sun and beach tourism model in the Valencian Region: action guidelines for territorial and sectorial policies}

The Comunidad Valenciana [Valencian Autonomous Region] is obviously no stranger to the current situation of mature tourist destinations and to the new demand trends. This becomes evident in the main territorial and tourism-related strategies put forward by the Valencian Government. Thus, by way of example, both the Estrategia Territorial de la Comunidad Valenciana [Valencian Region's Territorial Strategy] (2009) and the Plan de Acción Territorial del Litoral de la Comunidad Valenciana [Territorial Action Plan for the Valencian Region Coast] mention the need to put in value the natural, cultural and landscape values with a special focus on PNAs. Along these same lines, the Plan de Espacios Turísticos de la Comunidad Valenciana [Plan for Tourist Areas in the Valencian Region] (2006) additionally incorporates the extension of the protected land as an opportunity for tourism development, referring also to the need to rationalise and manage tourist activity within the PNA network.

Likewise, from the point of view of the competent administration in environmental matters, it is worth highlighting how it has reoriented its approach and action lines, passing from 'out-and-out' protection to the provision of more room for traditional activities and public use, which in turn facilitates a better socioeconomic integration of protected areas into their immediate territorial context. At the same time, we have witnessed during the last few years the start of a drawing-up process for public use plans that is in tune with the recommendations contained in the Plan de Acción para los Espacios Protegidos del Estado Español [Action Plan for Protected Areas in Spain] (2002-2008). This process has been accompanied by the preparation of resource inventories and studies about the demand. We should equally highlight the creation of promotion management offices in the case of some parks, along with the boost given to the implementation of public use quality systems, the adhesion to CETS and the proposal for the introduction of the sign Marca Parcs Naturals de la Comunitat Valenciana [Valencian Region's Natural Parks Brand]. This last project still finds itself in a development phase and it is a quality stamp for the firms based on the area of socioeconomic influence of the natural parks that offer distinct products and services associated with those parks. A special emphasis must also be placed on the cooperation between environmental and tourism administrations that has led to proposals of great interest such as the establishment of a protocol for the collaboration between the Tourist Information Offices and the Natural Parks in the Valencian region. The aim behind this protocol is to ensure that all the offices have the same training processes as well as some obligatory standards that must be kept, as this will ultimately result in the provision of better 
information to the visitor and in a greater level of exchange between both of them.

In short, despite not having had enough time yet to assess the degree of development of some of these initiatives and, therefore, of the results derived from them, they undoubtedly give proof of the new orientation guiding PNA policy and management.

\section{Benidorm: basic features of its development model and arguments for its renovation}

Although Serra Gelada Natural Park is located in the municipalities of Altea, Alfàs del $\mathrm{Pi}$ and Benidorm, special attention must be paid to the last town because it has the largest proportion of protected areas within the Natural Park, more specifically $46.3 \%$ of its sea part and $61.1 \%$ of its land part. As explained above, Benidorm is the main tourist destination in the Valencian Region as well as the one which provides the highest number of visitors to this PNA. Its economic structure has specialised for more than 40 years now in the delivery of tourism services, which justifies its territorial and sociodemographic dynamics. This town with over 70,000 permanent inhabitants (2009) has the leadership in terms of urban hierarchy over the nearby areas, whereas its occupancy model urban, concentrated and intensive- is defined by a town-planning and building typology which has made density and verticality become its essential characteristics. As a coastal tourism destination, Benidorm exemplifies the situation of the resorts which emerged during the 1960s following the boom of mass tourism in Spain [11], with a high percentage of international demand and a considerable volume of formal regulated accommodation offer, especially in the hotel segment, as it has a total of 39,559 beds (2008), which represents $32.65 \%$ of the total for the Valencian Region. In fact, hotel availability has become the engine of specialisation for this destination and also an essential part of the local economy, based on the supply of sun and beach tourism addressed to demand segments with a medium purchasing power. Furthermore, occupancy levels are high all year round and, more precisely, according to data provided by the Instituto Nacional de Estadística (INE) [(Spanish) National Statistics Institute], hotel occupancy reached $76.25 \%$, a percentage well above the country's average $(53.5 \%)$. This percentage becomes even more significant if we bear in mind that it is a tourist destination characterised by its low seasonality -most of the hotel establishments in Benidorm stay open throughout the year. On the other hand, the average stay for a tourist who visits Benidorm is 6.25 days (INE, 2008), a figure that clearly exceeds the national average (3.24), although a tendency to shorten the stay in this resort has been checked in recent years.

The development of tourism in Benidorm has been associated from the very beginning with the marketing and commercialisation of a large part of its hotel offer through the large European tour-operators, mainly from the United Kingdom, who have moved large numbers of tourists under the 'package tour' modality. This explains the close link between Benidorm and British tourism, which simultaneously represents the main foreign emitting market for the Valencian Region (43\% of all the tourists coming from abroad). 
Although, for those same reasons, a comparison between Benidorm and other destinations in the Valencian Region reveals that Benidorm has a more positive tourist activity balance, there are some elements which make it advisable to undertake new action lines for the renovation of its offer. Among them would stand out, for instance, the new motivations of the demand (use of nonconventional intermediation channels, fragmentation/staggering of holidays, higher appreciation of the natural milieu, etc.), the deterioration of the destination's image, fundamentally associated with the sun and beach offer and night leisure (life), the stronger appeal of emergent tourist destinations, the excessive dependence on British tourism, the rise in the prices of services as a result of the adoption of a single currency, and the devaluation of the pound with respect to the euro or the submission to the conditions imposed by tour-operators.

\section{Characterisation of Serra Gelada Natural Park}

Within this tourist environment of such high frequentation is located Serra Gelada Natural Park (declared as such in 2005), the first maritime-terrestrial park in the Valencian Region. It includes a coastal mountain range, along with a few small islands and the surrounding sea waters with a total surface area of 5,654.97 ha., its terrestrial part being distributed between the city limits of Benidorm, l'Alfàs del Pi and Altea. In this emerged part, a small mountain alignment with a NE-SW orientation separates the bays of Altea and Benidorm, and its sixkilometre-long coastal front sinks directly into the sea forming cliffs of more than 400 metres which are of great interest, not only from the geomorphological (fossil dune) and botanical points of view but also from the perspective of the landscape in a territorial context with a high degree of anthropisation. Nevertheless, most of its surface corresponds to the marine milieu, in the submarine bottoms of which can be found numerous species of fish, crustaceans and other invertebrates which have turned it into one of the most interesting submarine zones in the Western Mediterranean, the vast prairies of Posidonia oceanica and the rocky bottoms, such as those in La Llosa with an exceptional biological diversity, being some of its most outstanding features. The presence of one of the few Mular Dolphin populations settled in Iberian Peninsula waters deserves a special mention too. These values equally justify its designation as a Lugar de Interés Comunitario (LIC) [Place of Community Interest], and the specific case of the nearby islands designated as Zonas de Especial Protección para las Aves (ZEPA E-121) [Areas of Special Protection for Birds] because they house the largest known colony in the Valencian Region of the European Storm Petrel or species such as the Common Shag (or Green) Cormorant or the Audouin Seagull, all of them birds included in the National Catalogue of Endangered Species. For this reason, it will be one of the areas included in the future Red Natura 2000 network.

\subsection{Recreational and tourist uses in the park according to the visitor's motivation}

The demand that frequents the park largely coincides with the one visiting the Benidorm tourist destination: tourists who have as a specific motivation to spend 
their holidays in a sun and beach environment and who occasionally perform some activity in the area of the park, which usually consists in the visit to the Benidorm Island (3.4 km. away from Benidorm) or in making some hiking or trekking route along the range. It is also worth mentioning the visits of organised groups for an educational-environmental purpose which are common throughout the network of Natural Parks in the Valencian Region, as well as those of very small, isolated groups linked to specific activities, e.g. the monitoring of the storm petrel colony. We would finally like to highlight the only group whose specific motivation lies in the ecological values of the park in its sea bottoms, that of scuba divers, who mainly visit the rocky bottoms of La Llosa near the Benidorm Island.

Looking at the geographical distribution of visitors in this natural area (136,545 in 2008), it can be seen that the most substantial part of the visitors that the park receives is basically distributed across three areas: the Benidorm Island, which is visited as a maritime excursion or in a more minority fashion as a scuba-diving zone; the mountain range itself and, finally, the area comprising the sea bottoms of La Llosa, located some 300 metres away from the Benidorm island.

In addition to the facilities mentioned in the table, the park has a technical office for its management and an information point near the start of L'Albir route. As can be seen in the table, the land routes in the natural park are unevenly equipped. Whereas the Faro de l'Albir and Punta del Cavall routes have diverse public use facilities, the one which crosses the summit of Serra Gelada has hardly any infrastructures. However, there are still interesting resources in these routes which are not adequately exploited, e.g. the lighthouse itself and some ochre mines. The former is currently closed and its access is forbidden to the visitors who make the route, although the Alfàs del Pi Town Council has recently launched a project that would turn the lighthouse into a cultural and environmental space equipped with a great nature viewpoint. The second resource mentioned above corresponds to the most highly-developed artificial cave in the Alicante Province, with over 2,000 galleries, and represents one of the most significant ethnographic landmarks in the park. In this sense, there are also proposals for its putting into value that would include the fitting-out and cleaning of the mines and the organisation of guided tours through the inside, along with the introduction of a miners' train.

As for the Benidorm Island, it is most usually offered as a maritime excursion that operates with variable frequencies all year round (during the high season, the

Table 1: $\quad$ Possible tourist-recreational activities in the natural park context.

\begin{tabular}{|l|ll|}
\hline \multirow{3}{*}{ Water-based } & $\begin{array}{l}\text { Recreational Navigation (visit to the Benidorm Island, visit to the } \\
\text { Calpe and Altea destinations). }\end{array}$ \\
& $\begin{array}{l}\text { Diving and swimming (accessible coves around the range and the } \\
\text { Benidorm Island). }\end{array}$ \\
\hline Canoeing (the whole marine area of the Natural Park). \\
Land-based & $\begin{array}{l}\text { Hiking: Itinerary 1: L'Albir Lighthouse. Itinerary 2: Crossing Serra Gelada. } \\
\text { Itinerary 3: Punta del Cavall or Punta de la Escaleta. }\end{array}$ \\
\hline
\end{tabular}

Elaborated by the authors. 
Table 2: $\quad$ Public use infrastructures in the natural park itineraries.

\begin{tabular}{|c|c|c|c|c|}
\hline & L'Albir Lighthouse & $\begin{array}{c}\text { Punta del } \\
\text { Cavall }\end{array}$ & $\begin{array}{c}\text { Crossing } \\
\text { Serra Gelada }\end{array}$ & $\begin{array}{c}\text { Benidorm } \\
\text { Island }\end{array}$ \\
\hline Distance & $5 \mathrm{~km}$ & $5.2 \mathrm{~km}$ & $8 \mathrm{~km}$ & $0.5 \mathrm{~km}$ \\
\hline Difficulty & Low & Low & Medium-high & $\begin{array}{c}\text { Low- } \\
\text { medium }\end{array}$ \\
\hline Permitted Uses & Hiking and biking & Hiking and biking & Hiking & Hiking \\
\hline Infrastructures & $\begin{array}{c}\text { Car park, viewpoints, } \\
\text { tables and benches, } \\
\text { wastepaper baskets, } \\
\text { information panels, } \\
\text { recreational area }\end{array}$ & $\begin{array}{c}\text { Tables and } \\
\text { benches, waste- } \\
\text { paper baskets }\end{array}$ & - & $\begin{array}{c}\text { Wastepaper } \\
\text { baskets, } \\
\text { information } \\
\text { panels }\end{array}$ \\
\hline $\begin{array}{c}\text { Accessible } \\
\text { infrastructures }\end{array}$ & YES (partially) & YES (partially) & - & - \\
\hline
\end{tabular}

Elaborated by the authors.

frequency ranges between 5 and 6 daily trips). The journey to access the island has as its final stage a submarine vision of its sea bottoms from the boat itself. The scarce information supplied to the visitor does not mention the fact that it is located in a PNA. Neither does it include any other type of tourist, environmental or awareness-raising materials about the place being visited. Once the tourists are there, the range of activities available is rather limited: there is a route which takes them the highest part of the island from which they can enjoy excellent views of Benidorm's coast and it is also possible to practise scuba-diving or snorkelling, although these sports activities do not have an adequate promotion. The length of the tourist's stay on the island is therefore short.

In a nutshell, this is a PNA with a very high environmental value which offers numerous possibilities that can contribute to the diversification of the tourist offer in Benidorm, shaped as a strongly-developed tourist environment specialised in sun and beach that finds itself in an evident state of consolidation. As shown above, the tourist resources available in Serra Gelada Natural Park are mostly underdeveloped and underused, which is why it becomes necessary to carry out some actions meant to achieve a better exploitation of its potential.

\section{Proposals for the a better tourist exploitation of the natural park and its connection with Benidorm's tourist offer}

Below can be found some actions identified as suitable with a view to improve the tourist exploitation of Serra Gelada Natural Park by putting its resources in value from various perspectives. The goals would be to generate experiences and increase visitor satisfaction levels, to enrich Benidorm's tourist offer and, insofar as possible, to try to attract new demand segments.

\subsection{Proposals connected with the need to improve and reorient management from a tourist point of view}

This PNA can be no stranger to the tourist-recreational activities which take place in it and must be managed as what it is or what it can get to be, a tourist 
resource. It is consequently necessary to opt for a type of tourism management that would have a number of implications:

- Continuing the collaboration line already set in motion between the environmental and tourist administrations and focusing on it to an even larger extent.

- Adapting the public use offer to Benidorm's tourism reality, ensuring the existence of an adequate signposting that can not only show directions but also provide information and help in the interpretation of resources for a better optimisation of the visit, and making sure that the information supplied is in English given the high percentage of British tourists that it receives.

- Making possible a real and effective application of the planning and management instruments in the natural park which, on the one hand, can guarantee the preservation of the natural values which have justified its protection and which, on the other hand, can establish the rationalisation and management of any activity that is performed. Of course, it would be advisable for the park to have a public use plan.

- Putting the park in value and making the visitor aware of its importance and singularity in order to obtain suitable behaviours and improve the level of appreciation and understanding not only of the park but also of the experience it provides. Applying heritage interpretation as a tool for the management of the park's resources, since it can become the most effective and useful management instrument in order to achieve the conservation aims while at the same time a maximum dissemination of the value corresponding to these resources is made possible.

- Developing new self-financing formulas which bring a complementary source of income for the park and which, at the same, make it possible to offer more quality activities to visitors, for which the latter would be even willing to pay.

- Achieving a greater degree of involvement by the social agents directly or indirectly connected with nature-based activities. Preparing awareness and information campaigns about the possibilities offered by the Park for the diversification of the destination's tourist offer which would have as their addressees the public administrations and the tourism business sector.

\subsection{Proposals for the design of tourism products}

The design of tourism products must be done in tune with the zoning and the regulation of the uses and activities established in the environmental rationalisation instruments. Furthermore, the proposals should be adapted to public use plans and also include visitor management techniques and measures that can guarantee their positive effects on the social and economic environment. Therefore, it would be advisable to consider the following aspects when structuring tourism products:

- Creation of an inventory of resources with a tourism potential, that is, a set of natural and cultural attractions which can be structured for tourist use and 
enjoyment (e.g. ochre mines, fossil dunes, dolphins, scuba-diving zones in La Llosa, etc.).

- Exploitation of additional resources for the proposal of finalist offers associated with hiking or scuba-diving, for example. It is further suggested to articulate a product based on such activities which can bring together PNAs owning similar or complementary resources.

- Elaboration of in-depth studies about the demand, not only in aspects related to management but also to detect demand niches with specific motivations based on the park's most outstanding values - photography, ornithology, climbing and scuba-diving, etc.- so that a better structured product can be offered to them.

- A greater degree of involvement by the accommodation supply sector in the creation of tourism products connected with the natural park that favour extended stays rather than 'excursionist' trips.

- Encouraging the existence of specialised tour guides, either training the park's technical staff or making it easy to subcontract this key figure for the putting in value of the resources and for the right transmission of the message to visitors.

- An impulse to the setting-up of active tourism firms linked to scuba-diving which offer innovative and creative product initiatives and maintenance of adequate quality criteria for the already existing ones.

\subsection{Proposals oriented to achieve the best possible promotion and communication}

Similarly, it is necessary to carry out actions meant to disseminate and promote these areas through the use of more attractive, practical and interpretative materials and the introduction of new forms of communication. Some of these actions are listed below:

- Redesign of the natural park official brochure and also of the website for the Network of Natural Parks in the Valencian Region with a more innovative, appealing style, which provides contents and information with a more practical intent.

- Improvement of the information about the park offered in Benidorm's official website, as the information currently available is poor, scattered, not very attractive and hard to obtain.

- Collaboration between the different environmental and tourist Consellerias [Regional Government Departments] for the joint edition of materials more specifically focused on the world of tourism. Cooperation between administrations to attend certain fairs associated with specific tourism products: active tourism, nature photography, scuba-diving, etc.

- Implementation of alternative innovative marketing actions - among them street marketing or ambient media - meant to attract potential visitors who already find themselves at the destination.

- Use of Information and Communication Technologies (ICTs) in the promotion of the natural park. In other words, using the present-day 
interactive resources through the participation of the park management in social networks, virtual communities, travel blogs or websites 2.0.

- Shooting promotional videos about Benidorm in which more time is devoted to the activities connected with the natural park.

\section{Conclusions}

As for the assessment of national policies oriented to promote nature as a tourism product, these policies are scarce and additionally insufficient because they are strictly confined to PNAs accredited with the CETS in Protected Areas and Biosphere Reserves. Work is being carried out regionally on the necessary collaboration between environmental and tourist administrations, although still many more actions could be undertaken jointly. Moreover, there are recent planning instruments, like the ones mentioned above, which emphasise the need to put natural resources in value as a diversification element or their tourist revalorisation, although the level of implementation of the projects which incorporate these tools is still practically non-existent. In any case, apart from the interest that the aforementioned collaboration may have, it would also be advisable to have at our disposal a public use plan both for the PNA network as a whole and for each one of the natural parks in the Valencian Region, assigning more relevance to tourist-recreational activities, which could provide a framework for the design of products related to them. It can be inferred from the study of the case analysed that the tourist exploitation of many Natural Parks located in a coastal environment is still an unresolved matter for the destinations into which they are integrated, traditionally focused on the sun and beach product. In fact, although the study has essentially dealt with the relationship between Serra Gelada Natural Park and the Benidorm destination, the truth is that the situation we have described here can be extended to the rest of cases involving coastal destinations with PNAs. This situation is a consequence of the traditional model of specialisation in sun and beach tourism which has based its offer almost exclusively on these two elements of the natural milieu without using other resources of great interest to achieve wealth. Before this dynamics, the difficulty lies in changing the action patterns of tourist agents in whose approach there is no room for any other type of supply or demand. After all, on the one hand they are still tied to the decisions of the large tour operators and, on the other hand, too pleased with the success obtained so far. In this respect, it is of paramount importance for public as well as private agents to understand the interest and the opportunity that can result from making the most of those new resources in order to improve their offer and even to attract new demand segments beyond the high season. Of course, in the case of Benidorm it becomes absolutely necessary to achieve a close collaboration between the business sector and the local administration in order to define the main action lines of a strategy that seeks to put in value the natural spaces located in its environment, which include not only Serra Gelada and l'Illa but also other back-country mountain areas. A significant part of the strategy would have as its main concern to improve the information with well-prepared contents about these areas, the 
definition of products with a more active component and, of course, a promotion that goes beyond the dissemination of a tourist image identified with the 'ociurbe' ['leisure-metropolis'], in which a more prominent role must be given to PNA and to the recreational possibilities that they offer.

\section{Acknowledgements}

This work has been carried out within the framework of the research project "Renovation of coastal consolidated tourist destinations: new instruments for planning and management" of the Plan Nacional I+D+I 2008-2011 [2008-2011 R\&D\&I National Plan] by the Ministry of Science and Innovation, in which are involved researchers from the Castellón, Valencia and Alicante Universities.

\section{References}

[1] Vera Rebollo, F. (Coord.); López Palomeque, F.; Marchena, M.J. \& Antón, S. Análisis territorial del turismo. Ariel. Barcelona, 1997.

[2] Hall, C.M. \& Lew, A. (eds.). Sustainable tourism. A geographical perspective. Longman. New York, 1998.

[3] Perelli, O. \& Prats Palazuelo, F. La apuesta por la reconversión de los destinos maduros del litoral, Estudios Turísticos 172-173, pp. 203-321, 2007.

[4] Bramwell, B., Mass Tourism, Diversification and Sustainability Development in Southern Europe's Coastal Regions Coastal Mass Tourism. Diversification and Sustainable Development in Southern Europe, ed. B. Bramwell, Channel View Publications, Clevedon 1-31, 2004.

[5] Antón Clavé, S., De los procesos de diversificación y cualificación a los productos turísticos emergentes. Cambios y oportunidades en la dinámica reciente del turismo litoral, Papeles de economía española, 102, pp. 316333. 2004.

[6] Vera Rebollo, F., Turisme i territori. Realitats i reptes per a una nova etapa, des de la sostenibilitat como a referencia. Llibre verd del territorio valencià, ed. C. Miquel, Valencia, pp. 169-183. 2007.

[7] López Olivares, D.; Antón Clavé, S.; Navarro Jurado, E.; Perelli del Amo, O. \& Sastre Alberti, F., Cambios y transformaciones en el actual modelo turístico de España, Annals of Tourism Research en español, 7(2), pp. 423446, 2005.

[8] Agarwal, S., La reconversión del turismo costero. El ciclo de vida del destino turístico costero, Annals of Tourism Research en español, 4(1), pp. 1-36, 2002.

[9] Butler, R.W, (ed.). The tourism area life cycle. Applications and modifications, Channel View Publications, 2006.

[10] http://www.turismo2020.es

[11] Vera, F., Rodríguez, I. \& Capdepón, M., Reestructuración y competitividad en destinos maduros de sol y playa: la renovación de la planta hotelera de Benidorm en XIII Congreso Internacional de Turismo, Universidad y Empresa, Universitat Jaume I, Castellón, 2010. 